\title{
Sex ratios
}

\author{
SA West ${ }^{1}$, SE Reece ${ }^{1}$ and BC Sheldon ${ }^{2}$ \\ ${ }^{1}$ Institute of Cell, Animal and Population Biology, University of Edinburgh, UK; ${ }^{2}$ Edward Grey Institute, Department of Zoology, \\ University of Oxford, UK
}

Sex ratio theory attempts to explain variation at all levels (species, population, individual, brood) in the proportion of offspring that are male (the sex ratio). In many cases this work has been extremely successful, providing qualitative and even quantitative explanations of sex ratio variation. However, this is not always the situation, and one of the greatest remaining problems is explaining broad taxonomic patterns. Specifically, why do different organisms show so much variation in the amount and precision with which they adjust their offspring sex ratios?

Heredity (2002) 88, 117-124. DOI: 10.1038/sj/hdy/6800018

Keywords: adaptation; birds; constraints; natural selection; sex allocation; wasps

\section{Introduction}

Given that an organism reproduces sexually, how should it allocate resources to male and female reproduction? This decision has been termed sex allocation, and involves many related questions, ranging from what mating system is favoured (eg, separate sexes, or hermaphrodites with male and female reproductive organs), to how parental investment in individual offspring is expected to differ depending upon their sex (Charnov, 1982). Here we focus on the area of sex allocation research that has attracted the most attention: how individuals in species with separate sexes vary the proportion of their offspring that are male (termed the sex ratio).

Work on sex ratios has often been extremely successful (Charnov, 1982; Werren, 1987; Godfray and Werren, 1996; West et al, 2000a). Time and time again, sex ratio theory has been able to explain and predict variation in the sex ratio across species and populations, as well as facultative adjustment of offspring sex ratios by individuals in response to environmental conditions. This is best illustrated by considering some examples.

(1) Parasitic wasps (parasitoids) are insects whose larvae develop by feeding on the bodies of other arthropods, usually insects (Godfray, 1994). In many parasitic wasp species, where only one individual can develop per host, the size of the adult wasp depends upon the size of the host in which it was laid. It is thought that females gain a greater benefit from larger body size than males (although this has yet to be shown in the field; Godfray, 1994; West et al, 1996), in which case it would be advantageous to lay females in relatively large hosts and males on relatively small hosts. This pattern has been observed in a large number of species (Charnov et al, 1981; Godfray, 1994; West and Sheldon, submitted) (Figure 1a).

(2) The Seychelles warbler is a territorial bird endemic

Correspondence: SA West, ICAPB, University of Edinburgh, West Mains Road, Edinburgh EH9 3JT, UK. E-mail: stu.west@ed.ac.uk to a few islands in the Seychelles. In this species, daughters help their parents raise subsequent offspring, whereas sons disperse. In a high-quality territory (one with a high density of insect prey), having a helper is advantageous and so predominantly (90\%) females are laid, whereas in a low-quality territory (relatively few insects) the increased competition for food means that a helper is disadvantageous and it is mainly (80\%) males that are reared (Komdeur, 1996; Komdeur et al, 1997) (Figure 1b).

(3) Malaria (Plasmodium) and related protozoan parasites often have population structures that lead to considerable inbreeding (West et al, 2001a). When inbreeding occurs it leads to competition for mates between related males (ie brothers), which reduces the fitness return from producing males and favours the production of a femalebiased sex ratio (Hamilton, 1967; Read et al, 1992). Higher levels of inbreeding favour more female biased sex ratios, and consistent with this prediction, more female biased sex ratios are observed in populations where the prevalence of transmission stages (gametocytes) is lower and inbreeding rates are likely to be higher (Read et al, 1995) (Figure 1c).

One notable aspect of sex ratio theory is that relatively simple models are often able to predict patterns in empirical data extremely well (Charnov, 1982; Godfray, 1994; Chapuisat and Keller, 1999; West et al, 2000a; Herre et al, 2001). The main reasons for this success are that, in many cases, the predictions of sex ratio theory depend upon: (i) a simple and unavoidable trade-off (an offspring can be either male or female), and (ii) a small number of crucial variables which are easy to measure (eg, the size of a host, or the number of females on a patch) (Charnov, 1993; Seger and Stubblefield, 1996; Frank, 1998; West et al, 2000a). Indeed, in some areas the fit of data to theoretical predictions can be expected to be so close that sex ratio theory has been argued to have a predictive power almost comparable to that of the 'hard' sciences of chemistry and physics (Hamilton, 1996). This has allowed work on the sex ratio to (a) provide some of the best quantitative evidence for the relative importance of natural 
selection at the gene, individual, kin and population levels (Leigh et al, 1985; Beukeboom and Werren, 1992; Seger and Stubblefield, 1996; Chapuisat and Keller, 1999; West et al, 2000a), and (b) to address very general questions about the precision of adaptation and the limits on natu-

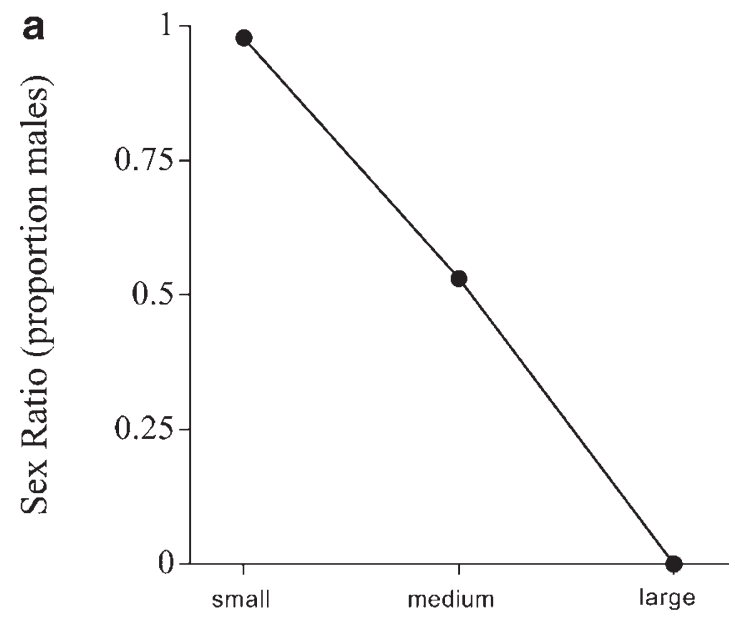

b

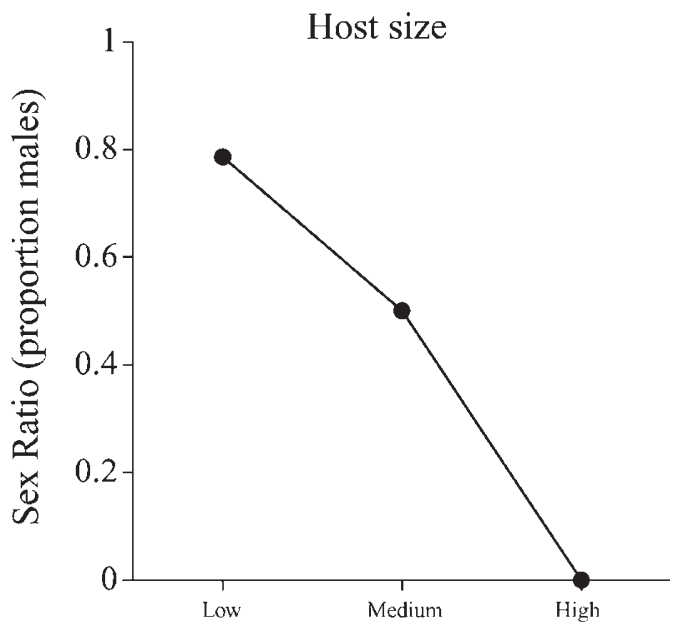

C

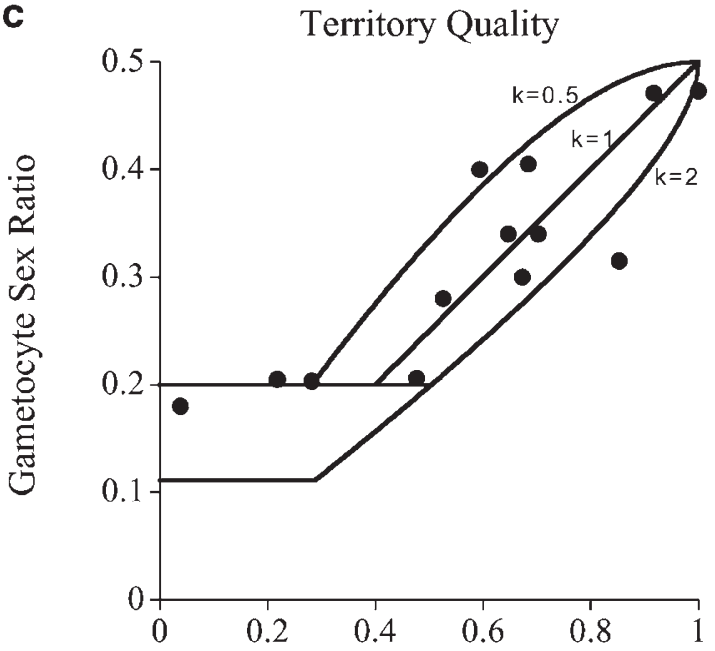

Gametocyte prevalence ral selection (Herre, 1987; West and Herre, 1998; Herre et $a l, 2001)$. In addition, reasoning has been reversed and observed sex ratios have been used to estimate parameters upon which the sex ratio is predicted to depend, but which can be difficult to measure directly (eg, the inbreeding rate in malaria parasites, which is a parameter of clinical importance (Read et al, 1992; West et al, 2000b, 2001a), the factor limiting reproduction in parasitic wasps (West and Rivero, 2000), or the relatedness between competing male fig wasps (West et al, 2001b)).

Despite these successes, it must be emphasized that the success of sex ratio theory is limited to a number of theoretical areas and taxonomic groups. For example, striking sex ratio patterns are rarely observed in vertebrates (Williams, 1979; Charnov, 1982). In our view, one of the biggest problems remaining for research into sex ratios and sex allocation is explaining broad taxonomic patterns. Specifically, why do different organisms show so much variation in the amount and precision with which they adjust their offspring sex ratios? In the rest of this paper we will focus on a number of issues relating to this question.

\section{Sex determination, adaptation and constraint in sex allocation}

Do organisms with chromosomal sex determination show facultative sex ratio variation? The conventional wisdom is that the mechanism of sex determination is a powerful constraint that determines the degree of sex ratio adjustment shown by an organism. Specifically: (a) the most striking sex ratio patterns have been found in the Hymenoptera (ants, bees, wasps), where the haplodiploid genetic system would apparently allow a female precise control of the sex ratio of offspring by deciding whether or not eggs are fertilized (males are haploid and develop from unfertilized eggs, whereas females are diploid and develop from fertilized eggs); (b) interesting sex ratio patterns are rarely found in vertebrates such as mammals or birds because chromosomal (genetic) sex

Figure 1 Some striking sex ratio examples. (a) In many parasitic wasps where only a single wasp develops per host, males are laid on small hosts and females on large hosts. Shown here are data from the pine bark weevil, Dolichomitus sp., parasitising Niphades variegates (Kishi, 1970). (b) In the Seychelles warbler, daughters help their parents to rear subsequent offspring, and thereby increase their parents' fitness. However, helpers are only useful on high quality territories where there are plenty of insects to eat; on low quality territories the presence of helpers increases competition for food, leaving less for nestlings. Parents show strong, and reproducible, biases in the primary sex ratio of their offspring depending on the quality of territory that they breed on, producing daughters on high quality territories, and sons on low quality territories (Komdeur, 1996; Komdeur et al, 1997). (c) The observed relationship between the sex ratio and gametocyte (sexual transmission stage) prevalence across populations of Leucocytozoon and Plasmodium parasites (Read et al, 1995). This positive relationship is predicted because when fewer hosts are infectious, transmission rates will be lower, mixed infections rarer, and the rate of inbreeding higher (Read et al, 1995). The solid lines show the predicted relationship for various degrees of parasite genotype (clone) aggregation ( $k$ represents the aggregation parameter from the negative binomial equation). 
determination (CSD) acts as a constraint to prevent facultative adjustment of offspring sex ratios (Maynard Smith, 1978; Williams, 1979; Charnov, 1982). It has been argued that this idea is supported by the fact that data on population sex ratios in birds and mammals show no consistent pattern, and represent just sample-size dependent noise around the sex ratio of 0.5 expected from a fair meiosis (Williams, 1979; Clutton-Brock, 1986; Bull and Charnov, 1988; Krackow, 1999; Palmer, 2000).

However, recent studies of taxa with CSD (mammals, birds, frogs, lizards, snakes, spiders) have reported shifts in offspring sex ratios consistent with adaptation (Madsen and Shine, 1992; Komdeur et al, 1997; Creel et al, 1998; Sheldon, 1998; Kruuk et al, 1999; Nager et al, 1999; Sheldon et al, 1999; Aviles et al, 2000; Sakisaka et al, 2000; Olsson and Shine, 2001). Furthermore, in some of these cases individuals appear to show extremely precise control of their offspring sex ratio. For example: (a) in the Seychelles warbler (described above), females vary the sex ratio of their offspring from $90 \%$ female to $80 \%$ male depending upon environmental conditions (Komdeur, 1996; Komdeur et al, 1997); (b) in the neotropical social spider Anelosimus domingo, mating occurs between the members of the same colony (between close relatives), so that females should only lay enough sons to mate their daughters - consistent with this prediction females produce, with very little variation, approximately one male for every nine females (Aviles et al, 2000); (c) for reasons that are unknown, Eclectus parrots often produce long unbroken runs of one sex that can only be explained by extremely precise control of the sex ratio at fertilization (eg, 20-30 males in a row) (Heinsohn et al, 1997). Although such extreme and precise sex ratio patterns are often observed in haplodiploid species, that they are seen in species with CSD suggests that constraints due to mechanisms of sex determination are not sufficient explanation for variation in sex ratio adaptation.

Resolution of whether species with CSD facultatively adjust their sex ratio in response to environmental conditions in a consistent manner requires comparison across studies. Unfortunately, previous comparisons across species have focused on population sex ratios (Williams, 1979; Clutton-Brock, 1986; Clutton-Brock and Iason, 1986; Palmer, 2000). This is problematic because in situations where we expect individuals to vary their sex ratio depending upon environmental conditions (as is the case with most vertebrate examples), with some individuals being expected to produce sons and others daughters (Trivers and Willard, 1973), it is extremely difficult to predict population sex ratios (Frank, 1990). Even in cases where it can be relatively easy to predict patterns of sex ratio variation across individuals, the overall population sex ratio is predicted to depend upon a variety of factors such as the details of male and female life histories, distribution of variation in maternal quality, the extent to which other behaviours (eg, clutch size) are facultatively adjusted, and the form of trade-off between current and future reproduction. (Frank, 1987, 1990; Frank and Swingland, 1988; Pen, 2000; Pen and Weissing, 2000a,b). Consequently, no a priori predictions can be made about population sex ratios, and inconsistent observations across species are not surprising (West and Sheldon, submitted).

West and Sheldon (submitted) have recently suggested that one way to solve this problem is to examine the pre- cision with which individuals facultatively adjust their offspring sex ratios in response to environmental conditions (rather than population sex ratios). Using this methodology West and Sheldon (submitted) showed that birds consistently adjust their offspring sex ratios in the direction predicted by theory. This provides strong evidence that even in vertebrates, CSD is not an all-powerful constraint that prevents adaptive sex ratio manipulation.

\section{How can we explain differences across taxa in the amount of sex ratio adjustment?}

West and Sheldon (submitted) also suggested that a simple cost-benefit approach, which considers many possible factors, provides a unifying framework for understanding variation across taxa in how much individuals adjust their offspring sex ratios. Specifically, that facultative sex ratio variation will only be favoured when the fitness benefits of this behaviour are greater than its costs. In cases where facultative sex ratio variation is favoured, it will evolve to a level where the benefits of any further (marginal) increase in the precision of sex ratio adjustment would be exactly outweighed by its cost. Consequently, the most extreme and precise sex ratio variation will be seen in species where the fitness benefits of facultative sex ratio adjustment are high, and the costs low.

What kind of factors will influence the cost and benefits of facultative sex ratio adjustment? (1) The mechanism of sex detrmination will influence the cost of adjusting sex ratios (Maynard Smith, 1980; Charnov, 1982; Leimar, 1996; Pen et al, 1999; Pen, 2000; Pen and Weissing, in press). For example, CSD can impose a cost that is heavily dependent upon the mechanism (eg, the cost of aborting a fertilized egg or embryo would depend heavily upon at what stage this is done). (2) The benefit of facultative sex ratio variation will depend upon how much fitness gain is to be made from shifting offspring sex ratios, which will be influenced by the strength and form of selection involved. For example, if an environment is only encountered very rarely, there will be weak selection to produce the 'correct' sex ratio in that situation (Herre, 1987). (3) The benefit of facultative sex ratio variation will also depend upon environmental predictability - the more accurately individuals can assess the relevant environmental factors that influence the optimal sex ratio, more extreme sex ratio shifts would be predicted (Charnov, 1982; West et al, 2000a; West and Sheldon, submitted). This view thus suggests that the degree of precision of sex allocation should be viewed as a trait subject to natural selection.

Is there any evidence supporting the potential importance of these factors? First, more extreme sex ratio patterns are observed in situations where selection can be inferred to be stronger. For example, fig wasp species show: (a) more extreme sex ratio shifts in more variable environments, when there is stronger selection to adjust sex ratios in response to environmental conditions (Herre, 1987; Herre et al, 2001), and (2) more precise (lower variance) sex ratios in situations where selection for precise sex ratios (stabilizing selection) is greater (West and Herre, 1998). Furthermore, many cases of extreme (and precise) sex ratio variation in species where 
the method of sex determination is likely to impose a heavy constraint (eg, CSD and pseudo-arrhenotoky, in spiders, aphids, snakes, mites), occur when there is intense competition between brothers for mates (local mate competition, LMC) and strong selection for extremely female biased sex ratios (eg, as low as 5\% males) (Yamaguchi, 1985; Foster and Benton, 1992; Madsen and Shine, 1992; Nagelkerke and Sabelis, 1998; Aviles et al, 2000).

Second, data on the extent to which parasitic wasps adjust their sex ratio in response to host size, as described above (see Figure 1a), support the idea that more extreme sex ratio shifting is seen in more predictable environments. In some species (idiobionts) females kill the host at oviposition (egg laying), and in such cases host size will be a reliable cue as to the resources that offspring will have available for development. However, in other species (koinobionts) the host is not killed by the female, and so can continue to grow, in which case host size at oviposition is a less reliable predictor of the resources that their offspring will have available for development (King, 1989). Consistent with the possible importance of environmental predictability, species in which the host was killed at oviposition (idiobionts) were more likely to show facultative sex ratio variation than species in which the host was not killed (koinobionts) (King, 1989). More generally, it might be argued that in many cases, environmental predictability in factors influencing sex ratio behaviour is likely to be greater for invertebrates (eg, assessing the number of females on a patch or host size) than for vertebrates (eg, assessing the amount of lactation that a female will be able to provide, or the heritable genetic quality of her mate).

Clearly this is an area in which further theoretical and empirical work is required. For example:

(1) Much of the discussion above is based upon verbal arguments. Theoretical models are required that can be used to predict variation in the amount (and precision) of sex ratio adjustment. These models should allow for the cost of sex ratio adjustment (Maynard Smith, 1980; Charnov, 1982; Leimar, 1996; Pen et al, 1999; Pen, 2000; Pen and Weissing, in press), and variation in the benefit due to factors such as environmental predictability (West et al, 2000a; West and Sheldon, submitted). Also useful would be formal genetic models that incorporated the effect of genetic constraints such as mutation and pleiotropy (Barton and Turelli, 1989).

(2) The cost of sex ratio adjustment will depend heavily upon the mechanism with which it is carried out (Pen and Weissing, in press). However, very little is known about this mechanism in organisms with CSD (Krackow, 1995). Even in organisms with haplodiploid sex determination, there is very little knowledge of the underlying genetics (Orzack and Parker, 1990; Orzack and Gladstone, 1994; West and Herre, in press; for data in plants see Campbell, 2000). Estimating fundamental genetic parameters be particularly important if genetic constraints play an important role in explaining variation in the precision of sex ratio adjustment.

(3) A major problem is that in cases where the offspring sex ratio is expected to be adjusted in response to environmental conditions, the observed pattern is often a gradual shift in response to environmental quality (eg, host size, Figure 1a), whereas theory predicts a threshold shift from all male to all female offspring at a critical value of the environmental variable (eg, at a certain host size, Figure 2; Charnov et al, 1981). This remains the case even when there are costs to sex ratio adjustment (Pen, 2000; Pen and Weissing, in press). It is clear that theory needs to be developed that can adequately predict gradual shifts in offspring sex ratios in response to variation in environmental quality. One possibility is uncertainty, with individuals making mistakes (Charnov et al, 1981; Leimar, 1996; Pen, 2000; Pen and Weissing, in press). However, even with uncertainty the slopes frequently remain very steep (similar to a threshold) unless extreme assumptions are made (eg, if the cost of deviating from a sex ratio increases exponentially the further you are from 50\% males). An alternative explanation might be genetic constraints, such as mutation or pleiotropy. Clearly formal genetic models of sex ratio adjustment are required, as well as empirical data to test them (eg, what is the mutability or pleiotropy of sex ratio behaviour?).

(4) In some vertebrates, the sex determination mechanism has evolved back and forth between CSD and environmental sex determination (ESD) on many occasions, especially in turtles (Janzen and Krenz, in press; Janzen, submitted). This suggests that the costs and benefits of different sex determination systems may vary dependent upon environmental conditions. This may depend upon selection for sex ratio adjustment, or in response to genetic (intragenomic) conflict over sex ratio adjustment (eg, mothers and offspring favouring a different sex ratio; Hamilton, 1967; Werren and Beukeboom, 1998; Werren and Hatcher, 2000; Beukeboom et al, 2001;

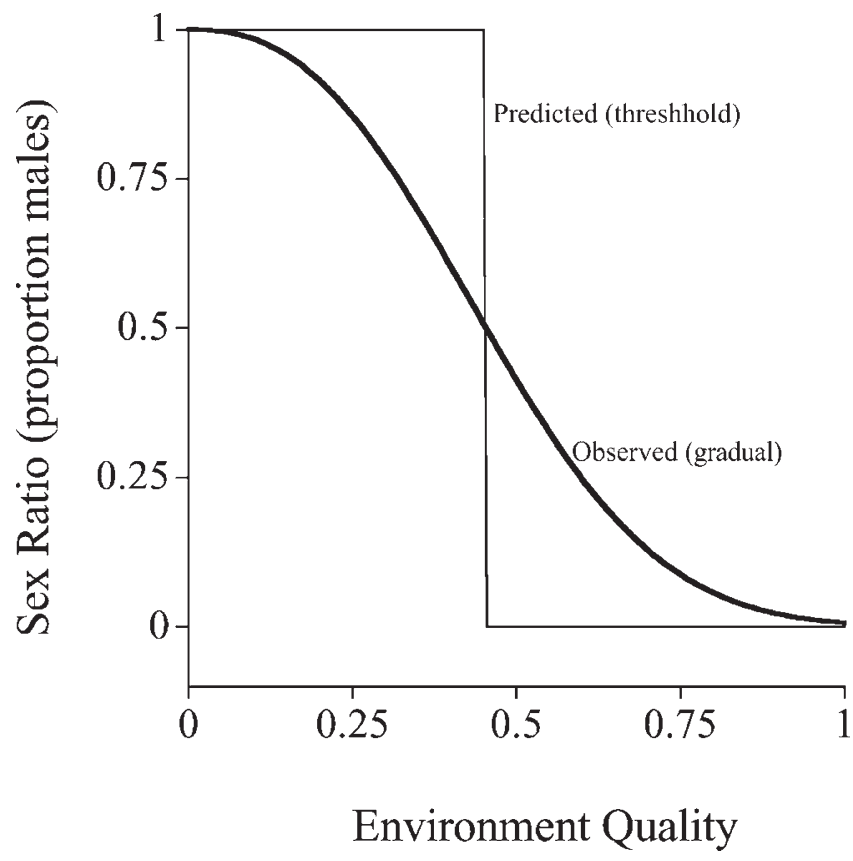

Figure 2 The pattern of conditional sex ratio adjustment - theory and reality. Plotted is the typical situation for the predicted and observed (thicker line) pattern of sex ratio adjustment in response to variation in environmental quality (eg, host size in parasitic wasps or maternal quality (dominance rank) in mammals). The theoretical prediction is usually to produce only one sex (in this case only males) below a threshold quality (eg, host size), and only the other sex (in this case only females) above that threshold. In contrast, empirical data usually shows a more gradual shift. 
Werren et al, submitted), and even cultural inheritance (Freedberg and Wade, 2001) may play a role. Given this, it is clear that there may be complex interactions between selection on the sex determination system and the sex ratio, and that in some cases the evolution of these two traits will need to be studied simultaneously. This approach might even help solve the enormous problem of explaining the occurrence in reptiles of ESD, and in some cases extremely female biased sex ratios (Shine, 1999; Freedberg and Wade, 2001; Janzen, submitted).

(5) Greater emphasis is required on comparative studies that examine variation in the extent (or precision) of sex ratio adjustment (eg, Herre, 1987; West and Herre, 1998; West and Sheldon, submitted), rather than population sex ratios (eg, Williams, 1979; Clutton-Brock, 1986; Clutton-Brock and Iason, 1986; Palmer, 2000). Especially useful would be studies in areas where theory is welldeveloped, and unambiguous a priori predictions can be made (West and Sheldon, submitted). Meta-analyses provide a useful methodology for such work.

(6) Direct tests of theoretical predictions could be made by varying the benefit of sex ratio adjustment (eg, through varying environmental predictability) in controlled laboratory selection experiments, and observing the consequences for sex ratio behaviour.

(7) There are very little data on how selection acts on the sex ratio in natural populations, and a particular shortage of experimental work (Komdeur (1998) provides an exception; for laboratory studies see: Conover and van Voorhees, 1990; Basolo, 1994; Varandas et al, 1997; Carvalho et al, 1998; Komdeur, 1998; Blows et al, 1999). However, such work is of considerable importance because without evidence that selection favours particular variants in the sex ratio it is difficult to assess whether observed patterns may represent adaptation. Explaining sex ratio patterns (or their absence) then becomes largely an exercise in ingenuity.

\section{Limits on our ability to explain sex ratios}

As the last section has suggested, very little is known about the way in which selection acts on sex ratio variation, or on any putative decision rules underlying this variation, in natural populations. Even in the absence of this information, it is worth stressing that we should not expect to find adaptation in the sex ratio in all cases. In organisms with complex life-histories (overlapping generations, extensive dispersal, subject to multiple life-history trade-offs) a large number of factors could influence sex allocation and there is no reason to assume that selection would act to favour one form of sex allocation behaviour over another. In particular, if selection varies over time, or between genetically connected populations, then there may be little likelihood of populations reaching local optima. Hence, we reiterate the need for studies measuring selection on sex ratios and sex allocation, preferably replicated over time and space (especially in vertebrates).

A second limit to our ability to explain sex ratios may lie in the fact that models of optimal sex allocation generally assume that the sex ratio is a trait exclusively under parental control (Bull and Charnov, 1988). This assumption may be violated in several ways. As noted above, genetic conflict may influence the evolution of sex determination mechanisms, but this may equally apply to the evolution of sex allocation. There is considerable clear evidence for intragenomic conflict over sex allocation (Hamilton, 1967; Werren and Beukeboom, 1998) - indeed, sex ratio distorting elements provide some of the clearest examples of 'selfish genes' that distort the sex ratio in order to maximize their own transmission, but to the determent of the fitness of the individual carrying them (eg, Werren et al, 1981). As Leigh (Leigh et al, 1985; Leigh, 1986) suggested, a chromosomal sex ratio distorting mechanism might be vulnerable to invasion by selfish genetic elements, in which case suppression of the mechanism by autosomal genes would be favoured. Part of the variation between species in the extent to which they adjust the sex ratio might simply represent stochastic variation in whether they had been subject to invasion by selfish genetic elements followed by autosomal suppression.

Another level of conflict over the sex ratio may be between parents and offspring (Trivers and Hare, 1976; Werren and Beukeboom, 1998; Werren and Hatcher, 2000). It is well appreciated that in haplodiploid species, relatedness asymmetries may lead to parents and offspring having different optimum sex ratios (eg, outbred mothers are equally related to sons and daughters favouring a sex ratio of 0.5 , whereas daughters are three times more related to sisters than brothers, favouring a sex ratio of 0.25 ; assuming the mother mated once). This has gained particular attention in the social insects, where theory is well developed, there is a large body of literature testing theory, and it seems that offspring can often win the conflict (Chapuisat and Keller, 1999; Sundstrom and Boomsma, 2000). Another reasonably clear example from the Hymenoptera arises in polyembryonic species (see Godfray, 1992; Grbic et al, 1992; Harvey et al, 2000). However, more generally, little is known about the resolution of parent-offspring conflict (ie who wins?). Furthermore, it is possibly less appreciated that if offspring are reared in family groups, interactions between different sexes of offspring may change the sex ratio, or the relative reproductive values of the two sexes of offspring (Pickering, 1980; Godfray, 1986; Ude et al, 1996; Nager et al, 2000). While the expected consequences of such intrabrood competition are worked out in some cases for the sex ratio at the level of the population (Godfray, 1986; West et al, 1999; Werren and Hatcher, 2000), it is not known how intersexual intrabrood competition would affect sex ratio adaptation at the level of individuals in response to environmental variation, particularly since the effects of competition between the sexes might be strongly context-dependent.

\section{Conclusions}

We have suggested that a major problem remaining for research into sex ratios and sex allocation is explaining why different organisms show so much variation in the amount and precision with which they adjust their offspring sex ratios. In order to address this problem we need to improve our understanding of constraints that may prevent 'perfect' behaviour, and to incorporate them into theory. This will require work from diverse areas - 
for example, behavioural ecology, physiology, mechanisms of sex determination, genetics (eg, what is the importance of pleiotropy or mutation). Clearly this will not be a trivial undertaking.

However, this work is also important more generally because sex allocation theory offers some of the best opportunities for studying the nature of constraints on adaptation and evolution by natural selection (Herre, 1987; Bull and Charnov, 1988; Seger and Stubblefield, 1996; West et al, 2000a; Herre et al, 2001; West and Herre, in press). Although it is widely acknowledged that constraints are important in evolution (Gould and Lewontin, 1979; Maynard Smith et al, 1985; Partridge and Sibley, 1991; Orzack and Sober, 2001), little progress has been made outside of sex allocation theory in quantifying exactly why, when and to what extent constraints are important (Bull and Charnov, 1988). Work on sex allocation, and especially sex ratios, is useful in this respect because it is one of the few areas in life history theory (Stearns, 1992) where we can hope for a reasonably quantitative fit between empirical data and the predictions of simple theoretical models. Put simply, if we cannot understand sex ratios, we cannot hope to understand most other life history traits, whose evolution usually depend upon far more complex trade-offs.

\section{Acknowledgements}

This paper is based on a talk given at the Genetics Society meeting on Sex. We thank: Nick Barton, Jonathan Hodgkin, Anne McLaren and Linda Partridge for organising the meeting, and inviting the talk; John Brookfield for organising the special edition of Heredity that has arisen from this meeting, and for inviting our contribution; Dave Allsop, John Brookfield and Jack Werren for comments on the manuscript. We are funded by the BBSRC, NERC and Royal Society.

\section{References}

Aviles L, McCormack J, Cutter A, Bukowski T (2000). Precise, highly female-biased sex ratios in a social spider. Proc Roy Soc Lond B 267: 1445-1449.

Barton NH, Turelli M (1989). Evolutionary quantitative genetics: how little do we know? Annu Rev Genet 23: 337-370.

Basolo AL (1994). The dynamics of Fisherian sex-ratio evolution: theoretical and experimental investigations. Am Nat 144: 473-490.

Beukeboom LW, Werren JH (1992). Population genetics of a parasitic chromosome: experimental analysis of PSR in subdivided populations. Evolution 46: 1257-1268.

Beukeboom LW, Jong TJD, Pen I (2001). Why girls want to be boys. Bioessays 23: 477-480.

Blows MW, Berrigan D, Gilchrist GW (1999). Rapid evolution towards equal sex ratios in a system with heterogamety. Evol Ecol Res 1: 277-283.

Bull JJ, Charnov EL (1988). How fundamental are Fisherian sex ratios? In: Harvey PH, Partridge L (eds). Oxford Surveys in Evolutionary Biology, Oxford University Press: Oxford, pp 96-135.

Campbell DR (2000). Experimental tests of sex allocation theory in plants. Trends in Ecol Evol 15: 227-232.

Carvalho AB, Sampaio MC, Varandas FR, Klackzo LB (1998). An experimental demonstration of Fisher's principle: evolution of sexual proportions by natural selection. Genetics 148: 719-731.

Chapuisat M, Keller L (1999). Testing kin selection with sex allocation data in eusocial Hymenoptera. Heredity 82: 473-478.
Charnov EL (1982). The Theory of Sex Allocation. Princeton University Press: Princeton.

Charnov EL (1993). Life History Invariants. Oxford University Press: Oxford.

Charnov EL, Los-Den Hartogh RL, Jones WT, van Den Assem J (1981). Sex ratio evolution in a variable environment. Nature 289: 27-33.

Clutton-Brock TH (1986). Sex ratio variation in birds. Ibis 128: 329

Clutton-Brock TH, Iason GR (1986). Sex ratio variation in mammals. Q Rev Biol 61: 339-374.

Conover DO, van Voorhees DA (1990). Evolution of a balanced sex ratio by frequency dependent selection in a fish. Science 250:1556-1558.

Creel S, Marusha Creel N, Monfort SL (1998). Birth order, estrogen and sex ratio adaptation in African wild dogs (Lycaon pictus). Anim Reprod Sci 53: 315-320.

Foster WA, Benton TG (1992). Sex ratio, local mate competition and mating behaviour in the aphid? Pemphigus spyrothecae. Behav Ecol Sociobiol 30: 297-307.

Frank SA (1987). Individual and population sex allocation patterns. Theoret Pop Biol 31: 47-74.

Frank SA (1990). Sex allocation theory for birds and mammals. Ann Rev Ecol Syst 21: 13-55.

Frank SA (1998). Foundations of Social Evolution. Princeton University Press: Princeton.

Frank SA, Swingland IR (1988). Sex ratio under conditional sex expression. J Theoret Biol 135: 415-418.

Freedberg S, Wade MJ (2001). Cultural inheritance as a mechanism for population sex-ratio bias in reptiles. Evolution 55: 1049-1055.

Godfray HCJ (1986). Models for clutch size and sex ratio with sibling interactions. Theor Pop Biol 30: 215-231.

Godfray HCJ (1992). Evolutionary biology - strife among siblings. Nature 360: 213-214.

Godfray HCJ (1994). Parasitoids. Behavioural and Evolutionary Ecology. Princeton University Press: Princeton.

Godfray HCJ, Werren JH (1996). Recent developments in sex ratio studies. Trends Ecol Evol 11: 59-63.

Gould SJ, Lewontin RC (1979). The spandrels of San Marco and the Panglossian paradigm: a critique of the adaptationist programme. Proc Roy Soc Lond B 205: 581-598.

Grbic M, Ode PJ, Strand MR (1992). Sibling rivalry and brood sex-ratios in polyembryonic wasps. Nature 360: 254-256.

Hamilton WD (1967). Extraordinary sex ratios. Science 156: 477-488.

Hamilton WD (1996). Narrow roads of gene land: I Evolution of social behaviour. WH Freeman: Oxford.

Harvey JA, Corley LS, Strand MR (2000). Competition induces adaptive shifts in caste ratios of a polyembryonic wasp. Nature 406: 183-186.

Heinsohn R, Legge S, Barry S (1997). Extreme biases in sex allocation in E Clectus parrots. Proc R Soc Lond B 264: 1325-1329.

Herre EA (1987). Optimality, plasticity and selective regime in fig wasp sex ratios. Nature 329: 627-629.

Herre EA, Machado CA, West SA (2001). Selective regime and fig wasp sex ratios: towards sorting rigor from pseudo-rigor in tests of adaptation. In: Orzack S, Sober E (eds). Adaptionism and Optimality, Cambridge University Press: Cambridge, pp 191-218.

Janzen FJ (Submitted). Challenges in understanding the evolution of sex-determining mechanisms in vertebrates. $J$ Evol Biol.

Janzen FJ, Krenz JG (in press). Phylogenetics: which was first, TSD or GSD? In: Valenzuela N, Lance V (eds). TemperatureDependent Sex Determination, Smithsonian Institution Press: Washington, pp.

King BH (1989). Host size dependent sex ratios among parasitoid wasps - does host growth matter? Oecologia 78: 420-426.

Kishi Y (1970). Difference in the sex ratio of the pine bark weevil 
parasite, Dolichomitus sp. (Hymenoptera: Ichneumonidae), emerging from different host species. Appl Ent Zool 5: 126-132.

Komdeur J (1996). Facultative sex-ratio biases in the offspring of the Seycheles warblers. Proc Roy Soc Lond B 263: 661-666.

Komdeur J (1988). Long-term fitness benefits of egg sex modification by the Seychelles warbler. Ecol Lett 1: 56-62.

Komdeur J, Daan S, Tinbergen J, Mateman C (1997). Extreme modification of sex ratio of the Seycheles Warbler's eggs. Nature 385: 522-525.

Krackow S (1995). Potential mechanisms for sex ratio adjustment in mammals and birds. Biol Rev 70: 225-241.

Krackow S (1999). Avian sex ratio distortions: the myth of maternal control. In: Proceedings of the 22nd International Ornithological Congress, pp 25-433.

Kruuk LEB, Cluttonbrock TH, Albon SD, Pemberton JM, Guinness FE (1999). Population density affects sex ratio variation in red deer. Nature 399: 459-461.

Leigh EG (1986). Ronald Fisher and the development of evolutionary theory. I. The role of selection. Oxford Surveys Evol Biol 3: 187-223.

Leigh JEG, Herre EA, Fischer EA (1985). Sex allocation in animals. Experientia 41: 1265-1276.

Leimar O (1996). Life-history analysis of the Trivers and Willard sex-ratio problem. Behav Ecol 7: 316-325.

Madsen T, Shine R (1992). Sexual competition among brothers may influence offspring sex ratios in snakes. Evolution 46 1549-1552.

Maynard Smith J (1978). The Evolution of Sex. Cambridge University Press: Cambridge.

Maynard Smith J (1980). A new theory of sexual investment. Behav Ecol Sociobiol 7: 247-251.

Maynard Smith J et al (1985). Developmental constraints and evolution. Q Rev Biol 60: 265-287.

Nagelkerke CJ, Sabelis MW (1998). Precise control of sex allocation in pseudo-arrhenotokous phytoseiid mites. J Evol Biol 11: 649-684.

Nager RG, Monaghan P, Houston AI (2000). Parental condition, brood sex ratio and differential young survival: an experimental study in gulls (Larus fuscus). Behav Ecol Sociobiol 48: 452-457.

Nager RG, Monaghan P, Griffiths R, Houston DC, Dawson R (1999). Experimental demonstration that offspring sex ratio varies with maternal condition. Proc Natl Acad Sci USA 96: $570-573$.

Ode PJ, Antolin MF, Strand MR (1996). Sex allocation and sexual asymmetries in intra-brood competition in the parasitic wasp Bracon hebeter. J Anim Ecol 65: 690-700.

Olsson M, Shine R (2001). Facultative sex allocation in snow skink lizards (Niveoscincus microlepidotus). J Evol Biol 14 120-128.

Orzack SH, Parker ED (1990). Genetic variation for sex ratio traits within a natural population of a parasitic wasp. Genetics 124: 373-384

Orzack SH, Gladstone J (1994). Quantitative genetics of sex ratio traits in the parasitic wasp, Nasonia vitripennis. Genetics 137: 211-220.

Orzack SH, Sober E (2001). Adaptionism and Optimality. Cambridge University Press: Cambridge.

Palmer AR (2000). Quasireplication and the contract of error: lessons from sex ratios, heritabilities and fluctuating asymmetry. Annu Rev Ecol Syst 31: 441-480.

Partridge L, Sibley R (1991). Constraints in the evolution of life histories. Phil Trans Roy Soc Lond B 332: 3-13.

Pen I (2000). Sex allocation in a life history context. PhD Thesis, Groningen.

Pen I, Weissing FJ (2000a). Sex ratio optimization with helpers at the nest. Proc Roy Soc Lond B 267: 539-544.

Pen I, Weissing FJ (2000b). Sexual selection and the sex ratio: an ESS analysis. Selection 1: 59-69.

Pen I, Weissing FJ (in press). Optimal sex allocation: steps towards a mechanistic theory. In: Hardy ICW (ed) Sex Ratio Handbook, Cambridge University Press: Cambridge, pp.

Pen I, Weissing FJ, Daan S (1999). Seasonal sex ratio trend in the european kestrel: an ESS analysis. Am Nat 153: 384-397.

Pickering J (1980). Larval competition and brood sex ratios in the gregarious parasitoid Pachysomoides stupidus. Nature 283: 291-292.

Read AF, Anwar M, Shutler D, Nee S (1995). Sex allocation and population structure in malaria and related parasitic protozoa. Proc R Soc Lond B 260: 359-363.

Read AF, Narara A, Nee S, Keymer AE, Day KP (1992). Gametocyte sex ratios as indirect measures of outcrossing rates in malaria. Parasitology 104: 387-395.

Sakisaka Y, Yahara T, Miura I, Kasuya E (2000). Maternal control of sex ratio in Rana rugosa: evidence from DNA sexing. Mol Ecol 9: 1711-1715.

Seger J, Stubblefield JW (1996). Optimization and adaptation. In: Rose MR, Lauder GV (eds) Adaptation, Academic Press: San Diego, pp 93-123.

Sheldon BC (1998). Recent studies of avian sex ratios. Heredity 80: $397-402$.

Sheldon BC, Andersson S, Griffith SC, Ornborg J, Sendecka J (1999). Ultraviolet colour variation influences blue tit sex ratios. Nature 402: 874-877.

Shine R (1999). Why is sex determined by nest temperature in many reptiles. Trends Ecol Evol 14: 186-189.

Sundstrom L, Boomsma JJ (2000). Reproductive alliances and posthumous fitness enhancement in male ants. Proc $R$ Soc Lond B 267: 1439-1444.

Stearns SC (1992). Evolution of Life Histories. Oxford University Press: Oxford.

Trivers RL, Willard DE (1973). Natural selection of parental ability to vary the sex ratio of offspring. Science 179: 90-92.

Trivers RL, Hare H (1976). Haplodiploidy and the evolution of the social insects. Science 191: 249-263.

Varandas FR, Sampaio MC, Carvalho AB (1997). Heritability of sexual proportion in experimental sex ratio populations of Drosophila mediopunctata. Heredity 79: 104-112.

Werren JH (1987). Labile sex ratios in wasps and bees. Bioscience 37: 498-506.

Werren JH, Beukeboom LW (1998). Sex determination, sex ratios and genetic conflict. Annu Rev Ecol Syst 29: 233-261.

Werren JH, Hatcher MJ (2000). Maternal-zygotic conflict over sex determination: effects of inbreeding. Genetics 155: 14691479.

Werren JH, Hatcher MJ, Godfray HCJ (Submitted). Maternaloffspring conflict leads to the evolution of dominant zygotic sex determination. Heredity.

Werren JH, Skinner SW, Charnov EL (1981). Paternal inheritance of a daughterless sex-ratio factor. Nature 293: 467-468.

West SA, Herre EA (1998). Stabilizing selection and variance in fig wasp sex ratios. Evolution 52: 475-485.

West SA, Rivero A (2000). Using sex ratios to estimate what limits reproduction in parasitoids. Ecol Lett 3: 294-299.

West SA, Herre EA (in press). Using sex ratios: why bother? In: Hardy ICW (ed) Sex Ratio Handbook, Cambridge University Press: Cambridge, pp.

West SA, Sheldon BC (submitted). Constraints in the evolution of facultative sex allocation.

West SA, Flanagan KE, Godfray HCJ (1996). The relationship between parasitoid size and fitness in the field, a study of Achrysocharoides zwoelferi (Hymenoptera, Eulophidae). J Anim Ecol 65: 631-639.

West SA, Flanagan KE, Godfray HCJ (1999). Sex allocation and clutch size in parasitoid wasps that produce single sex broods. Anim Behav 57: 265-275.

West SA, Herre EA, Sheldon BC (2000a). The benefits of allocating sex. Science 290: 288-290.

West SA, Smith TG, Read AF (2000b). Sex allocation and population structure in Apicomplexan (Protozoa) parasites. Proc $R$ Soc Lond B 267: 257-263. 
West SA, Reeece SE, Read AF (2001a). The evolution of gametocyte sex ratios of malaria and related apicomplexan (protozoan) parasites. Trends Parasitol 17: 525-531.

West SA, Murray MG, Machado CA, Griffin AS, Herre EA (2001b). Testing Hamilton's rule with competition between relatives. Nature 409: 510-513.
Williams GC (1979). The question of adaptive variation in sex ratio in out-crossed vertebrates. Proc $R$ Soc Lond B 205: 567580.

Yamaguchi Y (1985). Sex ratios of an aphid subject to local mate competition with variable maternal fecundity. Nature 318: 460-462. 